\title{
Learning from Mistakes Results in Increase of Corporate Value
}

\author{
http://dx.doi.org/10.3991/ijac.v6i3.3098 \\ Adamantios Koumpis \\ National University of Ireland, Galway, Republic of Ireland
}

\begin{abstract}
In the paper we approach the issue of learning from our mistakes from different schools of thought and with the use of different epistemological metaphors such as the intellectual capital. We pose emphasis to the relevance of mistakes to the overall individual and corporate learning process and make an attempt to valuate metaphors for assessing mistakes and their relation to corporate intellectual capital and wealth.
\end{abstract}

Index Terms-mistakes, learning, intellectual capital, metaphors, corporate value.

\section{MistakeS AND THEIR RELEVANCE IN THE CORPORATE PROCESS}

\section{A. Context of mistakes}

Mistakes comprise an essential part of any human activity; and though in the bibliography one can read much about their various patterns of occurrence and the impact these may have in learning [1, 2, 3], I personally tend to converge to the opinion that there are two main ways of learning: we either learn from other people's mistakes, or, bitterly, we learn from our own mistakes. In both cases the person needs to be sensitive and capable to (train himself/herself) identify mistakes; this means that one needs to learn how to learn from other people's or own mistakes, something that sadly many of us fail to do.

On mistakes, there is a wide grey scale area or a broad gamut of what makes something become a mistake; mistakes aren't digital, they are rather analog i.e. in many cases the difference between a successful move or decision and a bad one are within a hair's breadth and the thin red line between them is moving: what today can save you and make a legend out of you may tomorrow be the worst decision you ever made in business or in life.

On this, and next to a theoretical corpus of relevant bibliography, there is an equally important one based on case studies and practitioners' reports and findings such as [4] and [5]. However neither a bad decision [6] can be regarded ipso facto as a mistake, nor does the term corporate social responsibility or corporate governance help much in diminishing the individual's 'personal' role in mistakes and the underlying mistake-making process. Cases such as the BHP mine tailings in Papua New Guinea that caused environmental pollution, the case of Bayer's "Baycol/Lipobay" statin that incurred risk to human health and Mikasa's resale of tainted rice, each of which dates back to the 1980s, 1990s and 2000s, which are presented in [4] offer an extensive insight to the background story for each mistake.
Quite ironically the opposite also holds, namely something that was regarded as a mistake and had been attributed to a specific person, may at the end become a success story: in [5] the case of Iridium, a much promising venture in the area of telecommunications is presented. Its - then - CEO Edward Staiano had 'as late as 1998 [...] predicted Iridium would have 500,000 subscribers by the end of 1999'. Unfortunately, by April 1999, Iridium had only 10,000 customers and its CEO, Edward Staiano, resigned under pressure. However, and with a delay of almost twelve years, as of December 2011 Iridium had managed to achieve a base of approximately 523,000 subscribers (http://en.wikipedia.org/wiki/Iridium Communications\#Present_status) so, again, what is a mistake or not is also a matter of timescale and in a fast moving world we tend to label actions wrongly as mistakes.

Of course decisions are not made in vacuo: they are part of a wider context and one can always see and follow the trace of a good or bad decision to see what led to it. And it is therefore that our own mistakes as well as the mistakes of other people can be used as a shadow capital that will help us correct or improve things for the future.

To the above, there is a covert hypothesis that lies underneath: it all depends on whether the people are willing to recognize their own mistakes and learn out of them. And as far as other people are concerned, there is always our personal share even when considering other people's mistakes. I cannot imagine how someone can criticize his or her boss that s/he may have blindly supported for several years once that boss is kicked out. I know that as part of the scientific process is to bring factual data and evidence on any arguments - but this is not meant to be a conventional paper so I can afford to ask the readers to find some example cases from their own corporate and organizational environments.

\section{B. Provenance of mistakes}

It is said that "success has many fathers, failure is an orphan". So a first hindering factor for this to happen is that people in general tend to not (want to) see their mistakes straight into the eyes. By not doing this, and avoiding having a continuously open thread for examining and studying mistakes we disable ourselves from learning. A great part of a culture that asks people to admit their mistakes publicly does not seem to help much the learning process. Mistakes are part of our personality and in many cases reveal more about our characters and who we truly are - so admitting something as a mistake soon after it took place is more part of a show than a genuine act of remorse [7]. 


\section{SHORT PAPER}

\section{LEARNING FROM MISTAKES RESULTS IN INCREASE OF CORPORATE VALUE}

How should a CEO of an organization admit as a mistake that he preferred to fire people only because he wanted to keep himself under the payroll of the organization for the next 3 years? He will have to create a nest of excuses, grey and white lies and some reasoning explain why firing people helps the organization to regain its lost momentum, or rationalize its costs, or improve its activities or its value-creation opportunities for the future, etc. Many of the excuses may actually relate to the reasons that drove his or her decision. But again it is only within a hair's breadth to find the real cause and motive of such behavior.

And how can you manage to account executive managers and officers who may have been praised for many 'good' things they achieved but also condemned for certain others [8]? There is some collective experience when dealing with political leaders and how history and historians are used to treat them, usually when they are reporting on them within a biography, but for every Mao, Nixon or Hitler, there are (hundreds of) thousands of little Maos, Nixons or Hitlers out there, making mistakes for which they will never be accounted for.

\section{Stigmatisation of mistake}

Quattrone in [9] presents the development of accounting and accountability practices within the Society of Jesus from the $16^{\text {th }}$ to the $17^{\text {th }}$ centuries and argues that this cannot be reduced to an economic explanation that views them merely as tools for measuring and allocating economic resources thereby explaining the formation of hierarchies. Quite the opposite, their development and refinement needs to be considered as tightly linked to the absolutist ideology of the Roman Catholic doctrine of the Counter-Reformation, conceived as 'a complex work of compromise among theological, religious, political, institutional, and social instances, of which the hierarchical structure of the Order and its accounting records were only the visible traces'.

In the Christian West, it would be a mistake to not examine the role of Christianity, its dogmas and influence on the practices we developed with respect to the learning process and how much it is to be accounted for our tendency to leave out the role of mistakes from it.

It is not by chance that a legendary social psychologist with a pioneering research in the role of cultures across modern nations, has tried to revisit the seven deadly sins, as these were originally presented by the Catholic Church, in a multicultural world [10]. Hofstede argues that the seven specific sins in dealing with the culture concept: unawareness, ethnocentrism, amnesia, professional myopia, conceptual mix-up, academic polemics, and level confusion. And it is not by chance that entities like the European Commission in their official documentation [11] had used terms loaded with ethical connotation such as "in Europe a serious social stigma is attached to bankruptcy. In the USA bankruptcy laws allow entrepreneurs who fail to start again relatively quickly and failure is considered to be part of a learning process. In Europe those who go bankrupt tend to be considered as 'losers'. They face great difficulty in obtaining finance for a new venture." (emphasis added). This idea of "failure is considered to be part of a learning process' is for sure not new: repentance as an activity of reviewing one's action that involves a commitment to personal change [12] is not a matter of religious practice but a social process. Those who fail to practice it may be doomed not only to hell if we consider the theological level, but also to business or professional failure, if we consider the secular level.

\section{Mistake-enabling factors}

In a recent post entitled 'How to Get Ahead: Lie, Cheat and Steal' [13] Bruce Kasanoff doesn't take the traditional route, which at a significant part is also supported by the author, of considering mistakes and their lack of as the determinants of an ethical framework for corporate organisation and management. Instead of this, Kasanoff situates the ethical considerations related with certain actions such as lies, cheat or stealing to only refer to the ones used in the title of his post, with a culture and an attitude that makes each one of us as an individual either a giver or a taker. This theory is definitely an improvement - though, I am afraid, it can be misused to justify any means to an end practice that one can apply, and which can be regarded as positive if the subject of its introduction is a giver, while it can be blamed if the subject is considered as a taker.

Quattrone in a later paper [14] makes a quite innovative (and at some extent shockingly radical) comparison of common routine experiences such as the conduct of a case study related to the introduction of an ERP system to the ethical dilemma posed by Auschwitz, hence preparing the ground for what he calls 'the impossibility of the testimony and the need for testifying'. In our paper, this impossibility relates to the fact that a mistake at its onset has a different value and carries different contextual properties than at its conclusion or after some considerable time when it can be correlated and assessed as part of a given organizational or wider environmental setting.

Regarding our mistakes as case studies that we can continuously enrich with new data or findings from the outside world is a valid approach that can help us create value from a process that is actually painful and difficult.

Aiming towards a theory of mistakes would eventually help us in the daily routine tracking and tracing of mistakes. This can take place in a similar fashion like the monitoring of transactions within an ERP system and could help us produce MIS / EIS like reports that could be empowered through powerful data and information visualization techniques. This is not as difficult or unimaginable as it would be before ten or twenty years as enabling technologies for helping read brain activities and trends such as the Quantifiable Self movement $[15,16]$ can offer the support infrastructure for spotting mistakes on-the-fly and managing their correction dynamically.

\section{VAlue of Metaphors for Assessing MistakeS} AND RELATION TO CORPORATE INTELLECTUAL CAPITAL

\section{A. Role of metaphors}

A lot can be said about human nature and how it bears upon the success of initiatives to promote and support learning by individuals. A philosopher might emphasize self-interest and the individualistic nature of human beings. An economist, utility and the need to compete for resources. A sociologist might look at the desire for status or the need to compete for a mate. Whatever way you look at it, the bottom line remains the same: people will learn when they want to, and only with reasonable anticipation 


\section{SHORT PAPER}

of some sort of personal gain. In all other cases the entire initiative is destined to fail [17].

Learning is a very private matter. So, what is it that makes people apt in learning when they set themselves an autonomous learning goal, usually related to personal areas of interest such as cooking, advanced sexual technique, gardening or whatever else? And why do they exhibit suboptimal learning behaviour when the learning context is provided by someone else, by government, school, or, in the case of a corporate environment, the boss or the manager?

It is our belief that while for personal matters people are capable to show an increased degree of control over their learning processes and thus also on how to recognize, valuate and capitalize on their own mistakes, for professional and working contexts this does rarely happen. To this goal, an important asset may be found in the area of metaphors. Metaphors and the various conceptual schemes and mental representations that people use for carrying out most types of work tasks and job assignments, spanning from what we call 'simple' and 'everyday' to those we tend to regard as more abstract or sophisticated, and which work and the learning process in general are part of, have a great significance to the way tasks are carried out and work practices are developed for carrying out these tasks. By the use of such a immaterial or intangible culture [18], which is inherent to any specific job or learning assignment, being able to 'serve' it and to sufficiently express its characteristics, it is often possible to improve substantially the way a task is executed, no matter how abstract, complex, detailed or sophisticated may this be. That same immaterial or intangible culture also comprises ideas, values, norms, interaction styles, beliefs and practices that are used by the members of a community or forms parts of the society at large.

The work of Karl Popper, to whom [1] and [2] are also referring, was substantially influenced by the relative value of metaphors in the analysis of practical evidence and its employment for the creation of future theories which in this respect may have less need for validation as they come up as results of evidential sufficiency. (It is Popper who rethought the idea of foundationalism being a concrete set of assumptions or beliefs upon which knowledge is built in terms of relating it to a swamp in which pillars or structures are sunk to create foundations. The swamp implies that the empirical foundation of objective science is nothing absolute. Science and its structure and network of theories are a towering edifice that rises out of a swamp of uncertainty and possibility. The foundations are piers going down into the swamp from above. They do not reach a natural base; rather, they stretch down to the necessary degree to support the edifice of theory above [19].)

\section{B. Shadow capital of mistakes}

One aspect that has been discussed a lot in recent years, and that touches on the Knowledge Management issues, is the value of intellectual capital (IC) [20]. Stewart [21] defines IC as the combination of patents, processes, management skills, technologies, information about customers and suppliers, and experience. Over the years, businesses have found it difficult to contend with and account for intangible assets (same as it is the case with mistakes). The debate and discussions between the accounting profession, regulators and users of accounts attest to this. Therefore, this is a major reason for measuring IC to identify and utilize previously unrecognized assets. The increased use of IC measuring and reporting programmes is also attributable to the waning of accuracy in market valuations, the drive to decrease internal efficiencies and need for measures to achieve a specific company-related goal. To the present context, the inclusion of mistakes as part of a company's or an organisation's intellectual capital assets would be important and a catalyst for investors and shareholders as this would affect future performance of the entity.

In this respect intellectual capital can be regarded as a metaphor, an idea that has been supported by Christian Staam of the Centre for Research in Intellectual Capital from the Inholland University in Netherlands, because it describes the importance of all the intangible resources by stating the ability to use the human mind (intellectual) and financial wealth (capital), with which it can be compared. It is not only about the ability to use the human mind or financial wealth.

Companies provide many different types of services to their employees and stakeholders; the interactions between the abstract entity of a corporation and its people are mostly process-based and can be categorised as follows [22]:

- $\quad$ structured procedures or routines,

- $\quad$ semi-structured decision processes and

- negotiation-based case-solving.

In all the above, the role of mistakes and learning is essential though the types of learning and the typology of mistakes can vary significantly. Capurro [23] furthermore states that what can be managed is information or explicit knowledge and that implicit knowledge can only be "enabled". In this context, explicit means that a mistake can be clearly observed and expressed (and also digitalised), as opposed to implicit mistakes cannot be directly identified thus lying in a gray area defined by e.g. lack of skills or experiences, poor insight and intuition, false judgments, etc. When mistakes are explicit, they can be represented as declarative or procedural knowledge. We are aware that in the domain of cognitive sciences, the distinction between procedural and declarative models is related to the brain memory system - see for example [24], but here we use these terms in a limited sense, as defined in computer science:

- Declarative mistakes relate to facts and events in terms of concepts and relations, while

- Procedural mistakes relate actions to be taken in order to solve a problem step by step.

Mistakes are precious; mistakes are invaluable; mistakes are the shadow capital of any individual or company or organization. We have to foster a culture that supports people in recognizing their mistakes and keeping an open accounting process to continuously assess them and valuate them according to the original context that enabled their conduct, as well as later interpretations that may either signify an increase of the relative importance of a particular mistake, or a respective decrease. Mistakes can be thus treated as any corporate asset that is subject of documentation and reporting. In this regard, an accounting of (or alternatively: for) mistakes can prove useful as it will help justify people's decisions and the rationale underneath. 


\section{SHORT PAPER}

\section{LEARNING FROM MISTAKES RESULTS IN INCREASE OF CORPORATE VALUE}

\section{CONCLUSIONS}

Mistakes, whether resulting from defective judgment, deficient knowledge and carelessness, or resulting from misconceptions and misunderstandings are never trivial to deal with and can be approached as a source of potential corporate value so that they can facilitate future growth and development. Same as with gray problems that is a term used for IT problems where the causing technology is unknown or unconfirmed, mistakes are usually underestimated or not valuated in their true size. Human nature drives people to make emotional interpretations and seek simplicity; however, mistakes are not always the results of a higher-order complexity and can afford empathy-free interpretations. The stigma of failure and the elaborations usually related to the conduct of a mistake hinder us from learning and improving ourselves and our corporate performances from our mistakes.

In life, says Proust, we end up doing whatever we do second best. From ancient Greece through the Renaissance, the image was the servant of the idea. Then came philosophers who believed that art alone can give glimpses of truth. It is difficult in our times that people and organisations are haunted on the one side by a spirit of cruel lack of idealism and a culture of sharing, while on the other hand, quite paradoxically, they foster a daunting spirit of escapism from the perceived unpleasant or banal aspects of our daily and corporate realities, to support the process of recognizing and correcting mistakes but it is a one way.

Same as for Baudrillard [25] that the end of the Cold War was not caused by one ideology's victory over the other, but by the disappearance of the utopian visions that both the political Right and Left shared, mistakes can be ultimately relative occurences of what our society or our corporate culture does not regard as correct or right. However, same as with the accounting practices that govern corporate business transactions, an investment towards developing some common understanding on our mistakes can help improve our performance and increase our individual and corporate learning potentials.

Weaver in [26], presents the negative aspects and what we now perceive as the dark shadow of nominalism in the Western civilization since this doctrine gained prominence in the High Middle Ages. Leaving back the times of absolute truth, where a mistake can be any of the ones recognised in the "official" list of the ten commandments, to the times of what Weaver calls as the Great Stereopticon, namely a metaphor that aims to denote an emergent conceptual construct that serves to manipulate people's emotions and beliefs, and separate them from their humanity via "the commodification of truth", a mistake is anything that can be presented as such, employed and capitalised as such to serve the agendas of the part that made it or any other part that has a vested interest related to it. A CEO who fires several (tens, hundreds or thousands) of employees to protect shareholder value may be regarded as cruel for the means he employs but his ends may in general be appreciated or even praised. One rarely asks whether there may have been other means to protect shareholder value than 'demising' people [27], a euphemism that might had been used also in past times to denote physical extinction.

Raoul Vaneigem, one of the introducers of the Situationist movement in Europe supports that nothing is sacred and everything is permitted to be said [28]; however, there is a difference between something that is said i.e. expressed with words and concepts, and something that is materialised i.e. expressed with actions. Sadly for some of us, fortunately for the rest of the world, the world is not populated by intellectuals: the CEO who would dare to write an article sharing with a wide audience his idea about firing employees so that his company regains its strength and growth potential would face criticism and might get sacked the next day. But firing people as such may not cost him his position - at least not instantly. This brings us to some of the remarks we made in the opening of this article and which relate to the fact that nobody wants to openly talk about mistakes as they seem to diminish the value and the power of the person who makes them.

We now see an opportunity for change: the more we invest in explaining our mistakes to ourselves the easier we shall get rid of them and minimize the risks of making the same mistakes again. We humans can be inventive and creative and always come up with some new mistakes!

\section{REFERENCES}

[1] Berkson W. \& Wettersten, J. (1984) Learning from error: Karl Popper' psychology of learning. LaSalle, IL: Open Court Publishing.

[2] Perkinson, H.J. (1982) Education and learning from our mistakes, in P. Levinson (Ed.), In pursuit of truth: Essays on the philosophy of Karl Popper on the occasion of his 80th birthday (pp. 126-153). Atlantic Highlands, NJ: Humanities Press.

[3] Perkinson, H.J. (1984) Learning from our mistakes: A reinterpretation of twentieth-century educational thought. Westport, CT: Greenwood Press.

[4] Fred Robins (2010) Learning from corporate mistakes, Corporate Communications: An International Journal, Vol. 15 Iss: 2, pp.169 $-180$

[5] Finkelstein S. and Sanford S. H. (2000) Learning from Corporate Mistakes: The Rise and Fall of Iridium, Organizational Dynamics, 29 (2):138-148 http://dx.doi.org/10.1016/S0090-2616(00)00020-6

[6] Finkelstein S., Whitehead J., Campbell A. (2009) Think Again: Why Good Leaders Make Bad Decisions and How to Keep it From Happening to You, Harvard Business School Press.

[7] Brinke L., MacDonald S. et al. (2012) Crocodile tears: Facial, Verbal and Body Language Behaviours Associated With Genuine and Fabricated Remorse, Law and Human Behavior 36 (1): 5159, http://dx.doi.org/10.1037/h0093950

[8] Exline J., Fisher M. (2006) Self-Forgiveness versus Excusing: The Roles of Remorse, Effort, and Acceptance of Responsibility, Self and Identity 5: 127-46 http://dx.doi.org/10.1080/15298 860600586123

[9] Quattrone P. (2004) Accounting for God: accounting and accountability practices in the Society of Jesus (Italy, XVI-XVII centuries), Accounting, Organizations and Society 29 (2004) 647683, http://dx.doi.org/10.1016/j.aos.2004.03.001

[10] Hofstede G. (2011) Seven Deadly Sins: Temptations in a multicultural world for politicians, businesspeople, scientists, consultants and other responsible citizens, Whatsonmymind October 2011, Written reconstruction of introduction speech at the Hofstede Symposium hosted by the Hanze University of Applied Sciences at Groningen, the Netherlands, 16th September 2011, http://geerthofstede.nl/media/1510/whatsonmymindoct2011.doc, accessed on 25 May 2013.

[11] European Commission, Com (98) 222 Final, Fostering Entrepreneurship in Europe: Priorities for the Future, Communication from the Commission to the Council, Brussels, 07.04.1998

[12] Nave G. D. (2002) The Role and Function of Repentance in LukeActs, Academia Biblica 4, Brill Academic Pub, ISBN 9789004126947 


\section{SHORT PAPER}

\section{LEARNING FROM MISTAKES RESULTS IN INCREASE OF CORPORATE VALUE}

[13] Kasanoff B. (2013) How to Get Ahead: Lie, Cheat and Steal, http://www.linkedin.com/today/post/article/2013071812290636792-how-to-get-ahead-lie-cheat-and-steal, accessed at July 20 2013.

[14] Quattrone P. (2006) The Possibility of the Testimony: A Case for Case Study Research, Organization, Volume 13(1): 143-157, http://dx.doi.org/10.1177/1350508406059647

[15] Wolf, G. (2008). Quantified Self. Retrieved June 30, 2013, from www.aether.com: http://aether.com/quantifiedself

[16] Wolf, G. (2010). The Data-Driven Life. Retrieved July 13, 2013, from www.nytimes.com: http://www.nytimes.com/2010/05/02/ magazine/02self-measurement-t.html?pagewanted=all\& $\mathrm{r}=0$

[17] A. Koumpis (2010) Spending, Learning, Wasting, ACM eLearn magazine, April 2010. http://elearnmag.acm.org/featured.cfm? aid $=1773974$, accessed at 10 July 2013.

[18] Lakoff G. and Johnson M. (1980) Metaphors We Live By, Univ. of Chicago Press.

[19] Popper K. (1959) The Logic of Scientific Discovery, London: Hutchinson.

[20] Edvinsson, L. and Malone, M.S. (1997) 'Intellectual capital', The proven Way to Establish Your Company's Real Value by Measuring its Hidden Brainpower, London: HarperBusiness.

[21] Stewart, T.A. (1997) Intellectual Capital, The New Wealth of Organizations, New York: Doubleday.

[22] Lenk, K. and Traunmueller, R. (1999) Perspektiven einer radikalen Neugestaltung der oeffentlichen Verwaltung mit Informationstechnik, in: Oeffentliche Verwaltung und Informationstechnik. Schriftenreihe Verwaltungsinformatik, Heidelberg: Decker's Verlag.
[23] Capurro, R. (2004) Skeptical Knowledge Management, in Hobohm, H.-C., Knowledge Management: Libraries and Librarians Taking Up The Challenge (IFLA Publication, 108, 4757). Munich: Saur.

[24] Ullman, M. T. (2001) A Neurocognitive Perspective on Language: The Declarative/Procedural Model. Nature Reviews Neuroscience, 2(10), 717-26. http://dx.doi.org/10.1038/35094573

[25] Jean Baudrillard (2002) The Illusion of the End, in Selected Writings, p. 263, Second Edition, Stanford University Press.

[26] Richard M. Weaver (1948) Ideas Have Consequences, University of Chicago Press, ISBN 0226876802

[27] The Guardian (2013) Demised: HSBC's new euphemism for sacking people, http://www.theguardian.com/money/shortcuts/ 2013/apr/24/demised-hsbc-euphemism-sacking-people, accessed on June 292013.

[28] Raoul Vaneigem, Rien n'est sacré, tout peut se dire, La Découverte, Paris, 2003, 96 p. (ISBN 2-7071-4137-2)

\section{AUTHOR}

Adamantios Koumpis is Research Fellow at the Digital Enterprise Research Institute of the National University of Ireland, Galway (email: adamantios.koumpis@deri.org).

Manuscript received 26 July 2013. Published as re-submitted by the authors 15 November 2013 